\title{
Effects of the Demethylating Agent, 5-Azacytidine, on Expression of the Kallikrein-Kinin Genes in Carcinoma Cells of the Lung and Pleura
}

\author{
Joshua Wong, Yee Yen Sia, Neil L. Misso, Shashi Aggarwal, Angeline Ng, \\ and Kanti D. Bhoola
}

Lung Institute of Western Australia and Centre for Asthma, Allergy and Respiratory Research, The University of Western Australia, Ground Floor, E Block, Sir Charles Gairdner Hospital, Perth, WA 6009, Australia

Correspondence should be addressed to Kanti D. Bhoola, kdbhoola@gmail.com

Received 14 December 2010; Accepted 12 June 2011

Academic Editor: Allen Burke

Copyright ( $) 2011$ Joshua Wong et al. This is an open access article distributed under the Creative Commons Attribution License, which permits unrestricted use, distribution, and reproduction in any medium, provided the original work is properly cited.

\begin{abstract}
Tissue kallikrein (KLK1) and plasma kallikrein (KLKB1) may regulate the growth and proliferation of tumours of the lung and pleura, through the generation of kinin peptides that signal through the kinin $\mathrm{B}_{1}(B D K R B 1)$ and $\mathrm{B}_{2}$ (BDKRB2) receptors. The development and progression of cancer results from genetic mutations, as well as epigenetic changes that include methylation of DNA at CpG islands. The aim of this study was to assess whether expression of the kallikrein-kinin genes in lung cancer and mesothelioma cells is regulated by DNA methylation. Quantitative reverse transcriptase-PCR and immunocytochemistry showed differences in the basal expression of the kallikrein-kinin genes and proteins in lung carcinoma and mesothelioma cells, compared with non-malignant lung epithelial and mesothelial cells, respectively. Following treatment with the demethylating agent, 5-azacytidine (5-AZA), KLKB1 mRNA expression was consistently increased in both lung carcinoma and mesothelioma cells, whereas KLK1, BDKRB1 and BDKRB2 mRNA expression was decreased or unchanged. Increased expression of KLKB1 after 5-AZA treatment suggests it may function as a tumour suppressor gene in cancers of the lung and pleura. Studies on DNA methylation of the kallikrein-kinin genes will enhance understanding of their role in carcinogenesis and provide insights into the importance of kallikreins as tumour biomarkers.
\end{abstract}

\section{Introduction}

Lung carcinoma is one of the most common cancers in both males and females and is currently the most frequent cause of cancer mortality worldwide. Lung carcinogenesis is a multistep process that arises from the accumulation of genetic and epigenetic modifications, which lead to the emergence of invasive cancer cells. There is good evidence that longterm exposure to cigarette smoke carcinogens causes diffuse injury to the airway mucosal surface, supporting the concept that smoking drives the progression of lung carcinogenesis by inducing DNA fragmentation and constant disruption of the cell cycle [1]. In addition, epigenetic modification of genes may also contribute to the development and progression of lung cancer $[2,3]$.

Malignant mesothelioma develops on the protective membrane that lines the lung, and results from exposure to and inhalation of asbestos dust [4]. Asbestos dust fibres $(5-10 \mu \mathrm{m})$ usually penetrate into the lower respiratory tract, where they are phagocytosed by macrophages that migrate out from the lungs into the pleural mesothelium. These asbestos fibres are insoluble, and because they are not metabolized, remain in the pleura where they cause DNA breaks that result in the malignant transformation of mesothelial cells $[5,6]$.

Recent reports indicate that members of the serine protease family, generically known as tissue kallikreins (KLK115), are involved in carcinogenesis due to the induction of one or more of the kallikrein genes [7-11]. In particular hk1, the protein product of the classical tissue kallikrein (KLK1) gene, is known to hydrolyse macromolecules of the extracellular matrix, thereby promoting the invasiveness and metastasis of tumour cells [11]. Furthermore, mitogenic kinin peptides, formed by the proteolytic action of tissue 
kallikrein (KLK1) and plasma kallikrein (KLKB1) on the kininogen (KNG1) substrates, are known to regulate the growth and proliferation of tumour cells [12-14]. This is supported by the finding that the growth of lung small cell carcinoma cells is inhibited by dimeric kinin receptor antagonists $[15,16]$. The concept that KLK1 and KLKB1 are involved in the development of cancer and enhance the tumorigenic process is supported by our recent observations that the KLK1 and KLKB1 proteins are expressed in carcinomas of the lung and pleura $[17,18]$.

Tumours acquire a distinct pattern of genetic modifications, which are the result not only of heritable disruption of gene expression but also of epigenetic alterations [19]. Thus, the development and progression of cancer is due to both genetic mutations and epigenetic changes involving DNA methylation and histone modifications [20]. The best characterized epigenetic modification is aberrant hypermethylation of $\mathrm{CpG}$ islands in the promoter regions of genes, which results in inappropriate gene silencing [21]. The covalent methylation of DNA at CpG islands is catalysed by methyltransferases that methylate C- 5 of cytosine nucleotides. The question whether methylation of DNA is an important mechanism regulating the expression of the kallikrein-kinin genes in carcinomas of the lung and pleura has not been investigated previously. This study was designed to investigate the expression of mRNA for KLK1, KLKB1, KNG1, and kinin $\mathrm{B}_{1}$ (BDKRB1) and $\mathrm{B}_{2}$ (BDKRB2) receptors, following treatment of lung cancer and malignant mesothelioma cells with the DNA demethylating agent, 5-azacytidine.

\section{Materials and Methods}

2.1. Cell Culture. Nonmalignant transformed bronchial epithelial cells (BEAS-2B), lung adenocarcinoma cells (H2126), lung squamous cell carcinoma cells (H520), and a transformed epithelial-like mesothelial cell line (Met-5A) were obtained from the American Type Culture Collection (Manassas, Va, USA). Three malignant mesothelioma cell lines (LO68, NO36, and JU77) were derived from pleural effusions collected by thoracentesis of three patients with malignant pleural mesothelioma. All cells were cultured in Dulbecco's Modified Eagle Medium supplemented with 10\% foetal bovine serum, in a $5 \% \mathrm{CO}_{2}$ atmosphere at $37^{\circ} \mathrm{C}$.

\subsection{Treatment of Cells with 5-Azacytidine and Extraction of} $R N A$. Confluent cells were seeded at $3 \times 10^{5}$ cells/well in 6 -well culture plates, and after $24 \mathrm{~h}, 5$-azacytidine (5-AZA) ( 6.25 or $25 \mu \mathrm{M}$ ) was added to the cultures, using acetic acid as the vehicle. Control cultures were treated with acetic acid alone. Cells were harvested after $24 \mathrm{~h}$, and total RNA was extracted using RNeasy Plus Mini-kits (Qiagen, Melbourne, Australia). RNA ( $2 \mu \mathrm{g}$ per sample) was converted to cDNA using QuantiTect Reverse Transcription kits (Qiagen).

2.3. Quantitative Real-Time PCR. cDNA was amplified by quantitative real-time (q)PCR using TaqMan Gene Ex-pression primer/probes specific for the KLK1, KLKB1, BDKRB1, BDKRB2, and KNG1 genes, with human $18 \mathrm{~S}$
rRNA as an endogenous control (Applied Biosystems, Melbourne, Australia). qPCR was performed on a Bio-Rad iCycler instrument, using $25 \mu \mathrm{L}$ reactions containing $12.5 \mu \mathrm{L}$ of $2 \times$ TaqMan Universal PCR Master Mix, $8 \mu \mathrm{L}$ of RNase free $\mathrm{H}_{2} \mathrm{O}$ (Qiagen), $1.25 \mu \mathrm{L}$ of primer/probe for the gene of interest, $1.25 \mu \mathrm{L}$ of human $18 \mathrm{~S}$ rRNA primer/probe, and $2 \mu \mathrm{L}$ of cDNA. The PCR conditions were $95^{\circ} \mathrm{C}$ for $15 \mathrm{~min}$, followed by 45 cycles of $94^{\circ} \mathrm{C}$ for $15 \mathrm{~s}, 60^{\circ} \mathrm{C}$ for $30 \mathrm{~s}$ and $72^{\circ} \mathrm{C}$ for $30 \mathrm{~s}$. The threshold cycles $\left(C_{T}\right)$ were determined for each sample, and relative gene expression was calculated using the $2^{-\Delta \Delta C_{T}}$ formula [22], where $\Delta \Delta C_{T}=\left(C_{T \text {,target gene }}-C_{T, 18 S \text { rRNA }}\right)_{\text {Sample X }}-$ $\left(C_{T, \text { target gene }}-C_{T, 18 \mathrm{~S} \text { rRNA }}\right)_{\text {Sample } \mathrm{Y}}$.

For comparisons of basal gene expression, "Sample X" was the lung cancer or mesothelioma cell line of interest, and "Sample Y" was the comparator nonmalignant cell line (BEAS-2B or Met5A, as appropriate). In qPCR experiments assessing the effects of 5-AZA, relative gene expression was compared between 5-AZA-treated cells ("Sample X") and control cells treated with vehicle alone ("Sample Y"). Relative gene expression was plotted on histograms as fold differences or fold changes.

\subsection{Assessment of Protein Expression by Immunofluorescence} Labelling. Cells were seeded in 96-well plates (500-1000 cells/well) and cultured overnight before treatment with 5AZA or vehicle (acetic acid) for $24 \mathrm{~h}$. Cells were then fixed with acetone/methanol $(1: 1, \mathrm{v} / \mathrm{v})$ for $10 \mathrm{~min}$, washed with $0.01 \mathrm{M}$ PBS, pH 7.4, and nonspecific binding was blocked with $10 \%$ human serum, $10 \%$ goat serum, and Protein Block (Dako, Melbourne, Australia) for $15 \mathrm{~min}$. After washing with $0.01 \mathrm{M}$ PBS, pH 7.4, primary antibodies to tissue kallikrein, plasma kallikrein, kinin $\mathrm{B}_{1}$ receptor, kinin $\mathrm{B}_{2}$ receptor, and $\mathrm{H}$-kininogen $(1: 100$ dilution in $0.01 \mathrm{M}$ PBS with $1 \% \mathrm{BSA}$, $\mathrm{pH}$ 7.4) were added and incubated at room temperature for $3 \mathrm{~h}$. After washing $(3 \times 0.01 \mathrm{M}$ PBS $)$, AlexaFluor 488 conjugated anti-rabbit secondary antibody ( $1: 400$ dilution $)$ was added and incubated for $30 \mathrm{~min}$ in the dark. Cells were washed $(2 \times 0.01 \mathrm{M}$ PBS $)$ and incubated for $15 \mathrm{~min}$ with Hoechst 33342 nuclear stain (1:1000 dilution). Cells were washed $(3 \times 0.01 \mathrm{M}$ PBS $)$ and analysed using a GE In Cell Analyser 1000 microscope and software (Molecular Discovery Systems, Perth, Australia), which provided semiquantitative measurements of immunofluorescence intensity. The immunofluorescence images were edited using ImageJ software (National Institutes of Health, Bethesda, Md, USA), and the mean cytoplasmic fluorescence intensities were plotted as histograms.

2.5. Cytotoxicity of 5-Azacytidine. Cell proliferation assays were performed using CyQuant cell proliferation kits (Invitrogen, Melbourne, Australia). Cells were seeded in 96well plates $(5000$ cells/well $)$ and cultured for $24 \mathrm{~h}$ before treatment with 6.25 or $25 \mu \mathrm{M} 5$-AZA or vehicle (acetic acid). After $24 \mathrm{~h}$ cells were washed $(2 \times 0.01 \mathrm{M}$ PBS, $\mathrm{pH}$ 7.4) and stored at $-80^{\circ} \mathrm{C}$ for a minimum of $24 \mathrm{~h}$. Cells were thawed at room temperature, and cell lysis buffer containing CyQuant GR dye was added and incubated 


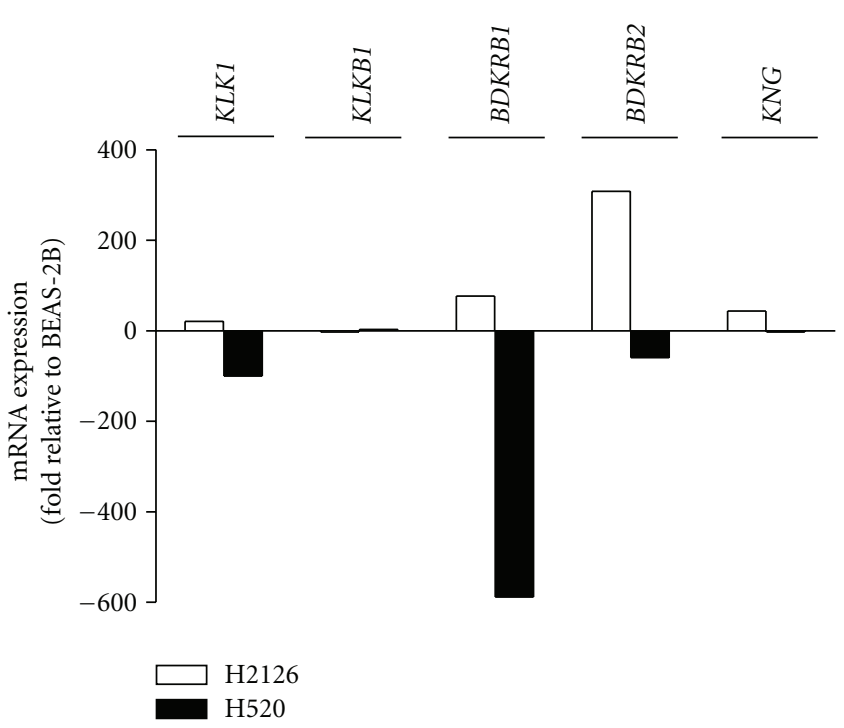

(a)

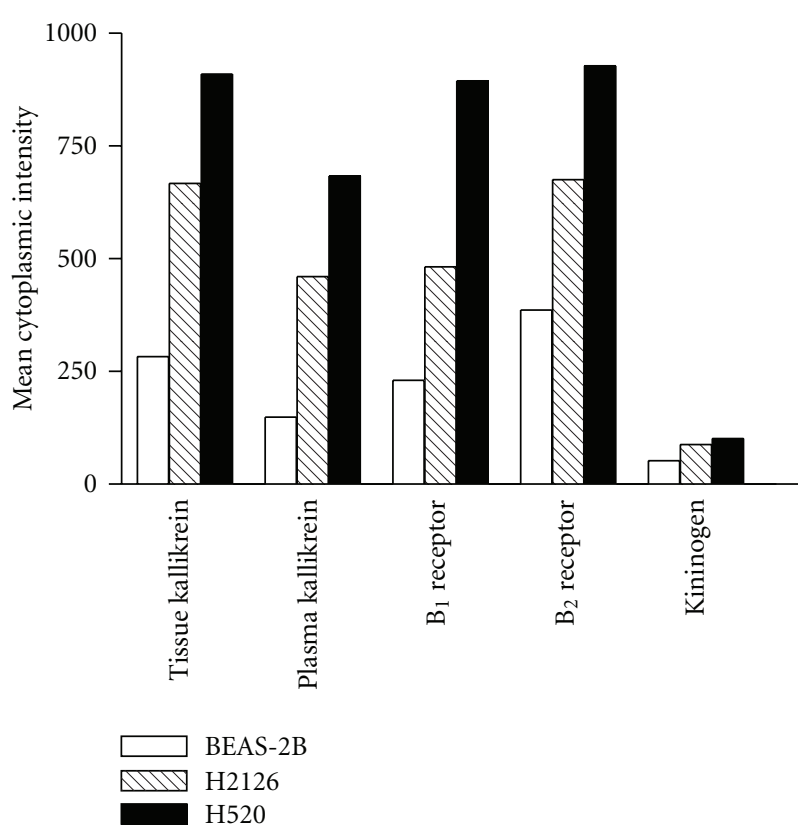

(b)

FIGURE 1: Basal kallikrein-kinin mRNA and protein expression in H2126 lung adenocarcinoma, H520 lung squamous cell carcinoma, and nonmalignant BEAS-2B lung epithelial cells. (a) Fold differences in mRNA expression for the tissue kallikrein (KLK1), plasma kallikrein (KLKB1), kinin $\mathrm{B}_{1}$ receptor (BDKRB1), kinin $\mathrm{B}_{2}$ receptor (BDKRB2), and high molecular weight kininogen (KNG1) genes in $\mathrm{H} 2126$ cells (white bars) and $\mathrm{H} 520$ cells (black bars) relative to that in BEAS-2B cells. (b) Mean cytoplasmic expression of the kallikrein-kinin proteins in BEAS-2B cells (white bars), H2126 cells (hatched bars), and H520 cells (black bars), as assessed by immunofluorescence labelling and image analysis.

for 2-5 $\mathrm{min}$ at room temperature. Fluorescence intensities were quantified on a Victor ${ }^{2} 1420$ fluorescence microplate reader (PerkinElmer, Melbourne, Australia) with excitation at $485 \mathrm{~nm}$ and emission at $530 \mathrm{~nm}$. Cell proliferation was quantified as the fold change in fluorescence intensity in 5AZA-treated cells relative to cells treated with vehicle alone.

2.6. Mapping of CPG Islands in the Kallikrein-Kinin Genes. The DNA sequences of the five kallikrein-kinin genes were obtained from the Entrez Gene database (National Center for Biotechnology Information, Bethesda, Md, USA), and sequences were refined using the Nucleic Acid Sequence Massager program (Attotron Biosensor Corporation, Carson City, Nev, USA). The CpG islands were located using the CpG Plot program (European Bioinformatics Institute, Hinxton, UK). Schematic gene maps were then constructed, showing promoter regions, introns, exons, and $\mathrm{CpG}$ islands within the five genes (Figures 5, 6, and 7).

2.7. Analysis of Data. Data is presented as mean values from two to three separate experiments; therefore, meaningful statistical analysis of the data was not possible. However, when interpreting the results, a 2-fold or greater change in mRNA expression was considered to be biologically significant.

\section{Results}

3.1. Basal Expression of Kallikrein-Kinin Genes and Proteins in Lung Carcinoma Cells and Normal Lung Epithelial Cells.
There was much greater expression of mRNA for KLK1 (21fold), BDKRB1 (77-fold), BDKRB2 (300-fold), and KNG1 (44-fold), but lower expression of KLKB1 mRNA (2.6-fold), in H2126 lung adenocarcinoma cells relative to that in nonmalignant lung epithelial (BEAS-2B) cells (Figure 1(a)). In contrast, expression of $K L K 1, B D K R B 1$, and $B D K R B 2$ mRNA was much lower in H520 lung squamous carcinoma cells (100-, 590-, and 60-fold, resp.) relative to that in BEAS$2 \mathrm{~B}$ cells.

Immunofluorescence labelling showed that basal expression of the kallikrein proteins $(\mathrm{hK} 1, \mathrm{hKB} 1)$ and the kinin $\mathrm{B}_{1}$ and $B_{2}$ receptor proteins was much greater in $\mathrm{H} 520$ squamous carcinoma cells than in BEAS-2B cells (Figure 1(b)). Expression of these proteins was also greater in $\mathrm{H} 2126$ adenocarcinoma cells than in BEAS-2B cells. However, expression of kininogen protein was similar in the two lung cancer cell lines and in BEAS-2B cells. The relatively greater expression of $h K 1, h K B 1$, and the $B_{1}$ and $B_{2}$ receptors, in H2126 compared with BEAS-2B cells, appeared to parallel the respective mRNA expression profiles in these two cell types. However, greater expression of $h K 1$ and the $B_{1}$ and $\mathrm{B}_{2}$ receptors in $\mathrm{H} 520$ cells compared with BEAS-2B cells contrasted with the lower mRNA expression in H520 cells.

3.2. Effects of 5-Azacytidine on the Expression of KallikreinKinin Genes in Lung Carcinoma Cells and Normal Lung Epithelial Cells. BEAS-2B, H2126, and H520 cells were treated with 6.25 or $25 \mu \mathrm{M} 5$-AZA for $24 \mathrm{~h}$, and mRNA 

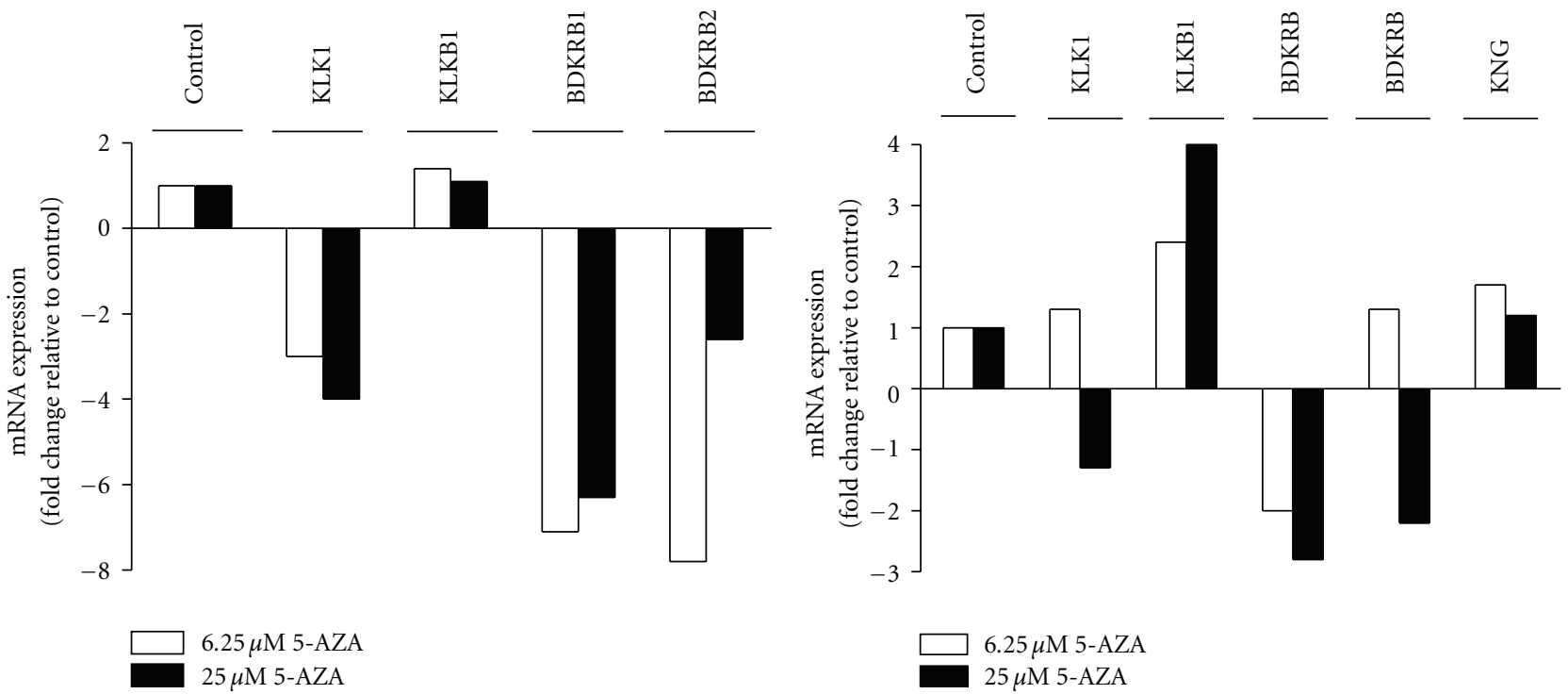

(a)

(b)

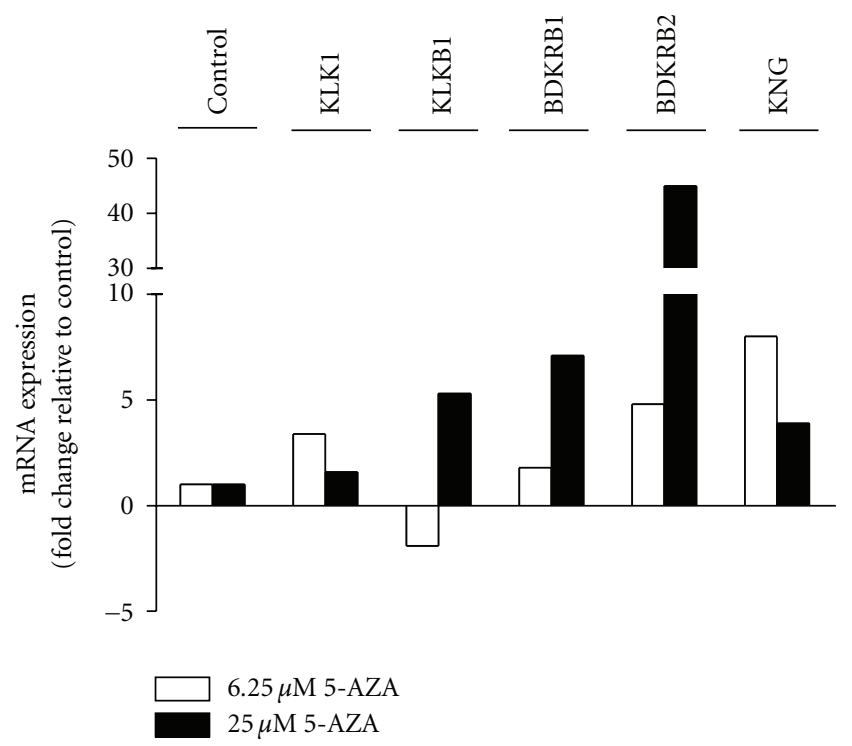

(c)

FIGURE 2: Effect of 5-azacytidine (5-AZA) on kallikrein-kinin mRNA expression in H2126 lung adenocarcinoma, H520 lung squamous cell carcinoma, and nonmalignant BEAS-2B lung epithelial cells. (a) Fold changes in mRNA expression for the tissue kallikrein (KLK1), plasma kallikrein (KLKB1), kinin $\mathrm{B}_{1}$ receptor $(B D K R B 1)$, and kinin $\mathrm{B}_{2}$ receptor (BDKRB2) genes, relative to vehicle control (arbitrarily set at 1), in BEAS-2B cells treated with $6.25 \mu \mathrm{M}$ (white bars) or $25 \mu \mathrm{M}$ (black bars) 5-AZA. (b) Fold changes in mRNA expression for the KLK1, $K L K B 1, B D K R B 1, B D K R B 2$, and high molecular weight kininogen (KNG1) genes, relative to vehicle control (arbitrarily set at 1), in H2126 cells treated with $6.25 \mu \mathrm{M}$ (white bars) or $25 \mu \mathrm{M}$ (black bars) 5-AZA. (c) Fold changes in mRNA expression for the KLK1, KLKB1, BDKRB1, $B D K R B 2$, and KNG1 genes, relative to vehicle control (arbitrarily set at 1), in H520 cells treated with $6.25 \mu \mathrm{M}$ (white bars) or $25 \mu \mathrm{M}$ (black bars) 5-AZA.

expression for the KLK1,KLKB1, BDKRB1, BDKRB2, and KNG1 genes was assessed, relative to that in control cells treated with vehicle (Figures 2(a)-2(c)). Treatment of BEAS$2 \mathrm{~B}$ cells with 6.25 or $25 \mu \mathrm{M}$ 5-AZA decreased expression of $K L K 1, B D K R B 1$, and BDKRB2 mRNA by $>2$-fold relative to control, whereas expression of the KLKB1 mRNA was unchanged (Figure 2(a)). Treatment of H2126 cells with 5AZA increased the expression of KLKB1 and decreased the expression of $B D K R B 1$ by $>2$-fold relative to control, whereas expression of the other genes was relatively unaffected (Figure 2(b)). In H520 cells, the most obvious effect of treatment with $25 \mu \mathrm{M}$ 5-AZA was the marked increase ( $>40$ fold) in BDKRB2 expression (Figure 2(c)). Expression of $K L K 1, K L K B 1, B D K R B 1$, and KNG1 mRNA in H520 cells was also increased by $>2$-fold relative to control, following treatment with either 6.25 or $25 \mu \mathrm{M}$ 5-AZA. 


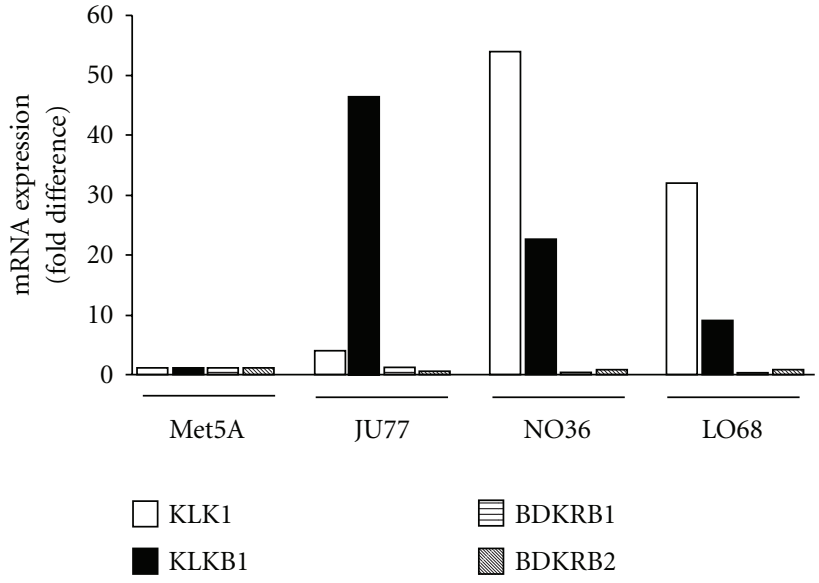

(a)

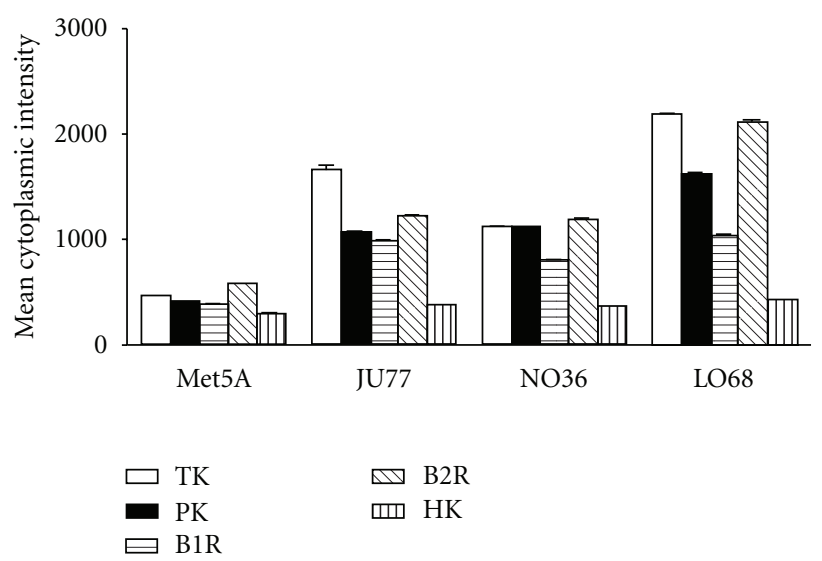

(b)

FIgURE 3: Basal kallikrein-kinin mRNA and protein expression in JU77, NO36, and LO68 malignant mesothelioma cells and in nonmalignant Met5A mesothelial cells. (a) Fold differences in mRNA expression for the tissue kallikrein (KLK1), plasma kallikrein (KLKB1), kinin $\mathrm{B}_{1}$ receptor $(B D K R B 1)$, and kinin $\mathrm{B}_{2}$ receptor $(B D K R B 2)$ genes in JU77, NO36, and LO68 cells, relative to that in Met5A cells (arbitrarily set at 1). (b) Mean cytoplasmic expression of tissue kallikrein (TK), plasma kallikrein (PK), kinin $\mathrm{B}_{1}$ receptor (B1R), kinin $\mathrm{B}_{2}$ receptor (B2R), and high molecular weight kininogen (HK) in Met5A, JU77, NO36, and LO68 cells, as assessed by immunofluorescence labelling and image analysis.

\subsection{Basal Expression of Kallikrein-Kinin Genes and Proteins} in Malignant Mesothelioma Cells and Normal Mesothelial Cells. Basal mRNA expression for the kallikrein-kinin genes in malignant mesothelioma cells (JU77, NO36, and LO68) was compared with that in the nonmalignant transformed mesothelial (Met-5A) cell line. KLK1 mRNA expression was greater in NO36 (>50-fold), LO68 (>30-fold), and JU77 cells ( $>2$-fold) compared with Met-5A cells (Figure 3(a)). Similarly, basal KLKB1 mRNA expression was greater in JU77 (>45-fold), NO36 (>20-fold), and LO68 cells (10fold) compared with Met-5A cells. Expression of BDKRB1 and BDKRB2 mRNA was similar in Met-5A cells and the malignant mesothelioma cells.

Basal expression of the kallikrein-kinin proteins in the malignant mesothelioma and Met-5A cells, as assessed by immunofluorescence labelling and image analysis, is shown in Figure 3(b). Expression of hK1, hKB1, and the kinin $\mathrm{B}_{1}$ and $\mathrm{B}_{2}$ receptor proteins was greater in JU77, NO36, and LO68 mesothelioma cells compared with nonmalignant Met$5 \mathrm{~A}$ mesothelial cells.

3.4. Effects of 5-Azacytidine on the Expression of KallikreinKinin Genes in Malignant Mesothelioma Cells and Normal Mesothelial Cells. Met-5A, JU77, NO36, and LO68 cells were treated with 6.25 or $25 \mu \mathrm{M} 5-\mathrm{AZA}$, and expression of KLK1, KLKB1, BDKRB1, BDKRB2, and KNG1 mRNA was assessed, relative to that in control cells treated with vehicle (Figures 4(a)-4(d)). In Met-5A cells, BDKRB1 mRNA expression was decreased (>8-fold) after treatment with $25 \mu \mathrm{M} 5$-AZA, but expression of the other genes was relatively unchanged (Figure $4(\mathrm{a})$ ). In JU77 cells, treatment with both 6.5 and $25 \mu \mathrm{M}$ 5-AZA decreased BDKRB1 and $B D K R B 2$ expression but increased KLKB1 expression by $>2$-fold (Figure 4(b)). Treatment of NO36 and LO68 cells with $25 \mu \mathrm{M}$ 5-AZA resulted in marked decreases (10- to 70 -fold) in the expression of KLK1, BDKRB1, BDKRB2, and KNG1 mRNA (Figures 4(c) and 4(d)). However, KLKB1 mRNA expression was increased $>5$-fold on treatment of NO36 cells with $6.25 \mu \mathrm{M}$ 5-AZA.

3.5. Cytotoxicity of 5-Azacytidine. Cell proliferation assays were performed to determine whether 5-AZA had any cytotoxic effects on the growth of the nonmalignant and carcinoma cells of the lung and pleura, which might indirectly alter gene expression. The results showed that at concentrations of 6.25 and $12.5 \mu \mathrm{M}$ 5-AZA had no significant effect on the proliferation of any of the cell types (data not shown).

\section{Discussion}

The development of cancer is associated with gene mutations and epigenetic dysregulation of the nucleosome. Epigenetic modifications cause changes in gene expression without changes in the DNA sequence, with DNA methylation and histone deacetylation being the primary epigenetic mechanisms. In tumours, about 60 to $70 \%$ of genes are methylated, resulting in silencing of these genes. Reversal of the methylation of promoter and/or transcription sites can be achieved by the use of demethylating agents such as 5AZA or DNA methyltransferase inhibitors.

We have previously shown that hK1, hKB1, and the kinin $B_{1}$ and $B_{2}$ receptors are differentially expressed in lung cancers and malignant mesotheliomas [17, 18]. Therefore, as a first step to understanding whether epigenetic modifications, and specifically DNA methylation, may contribute to the differential expression of the kallikrein-kinin genes in carcinomas of the lung and pleura, this study focused on the effects of the demethylating agent, 5-AZA, on mRNA 


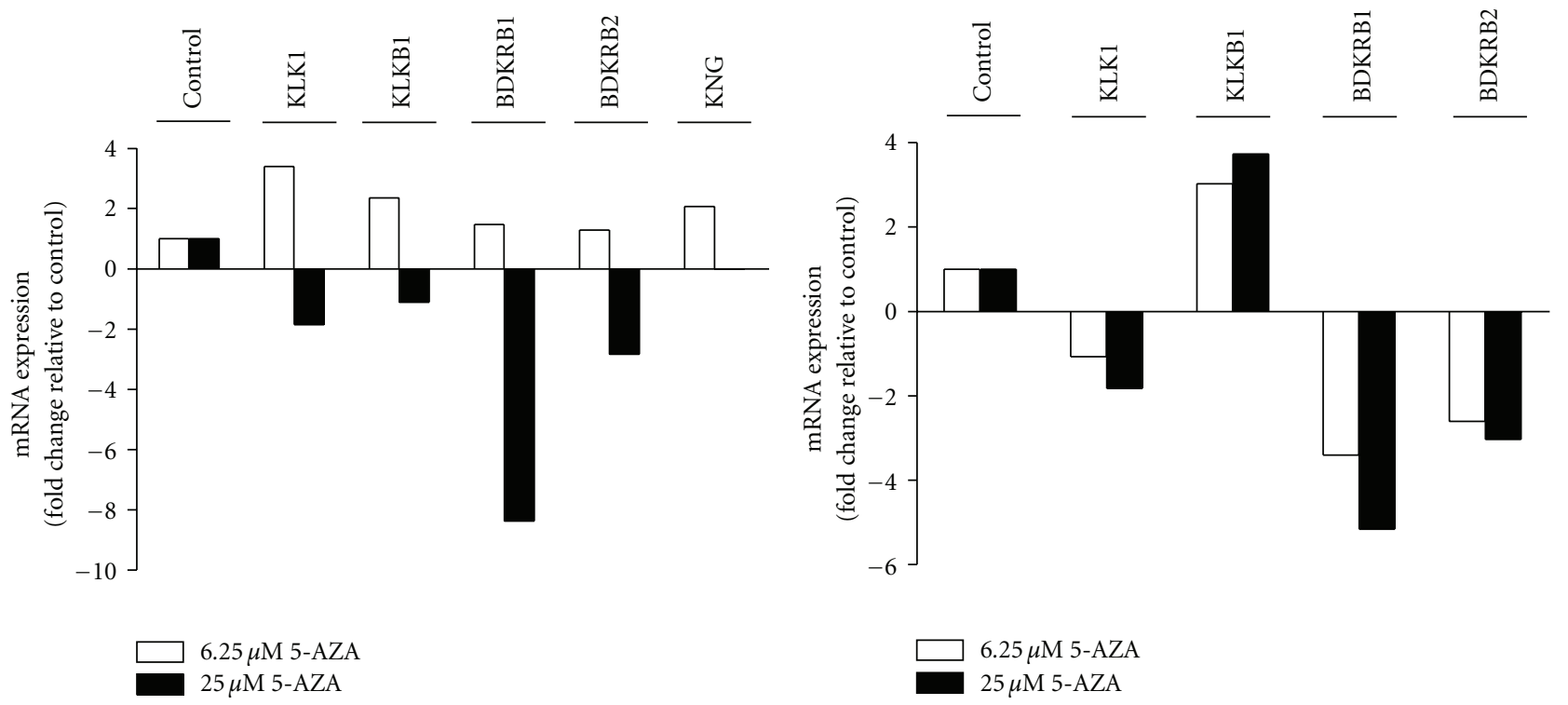

(a)

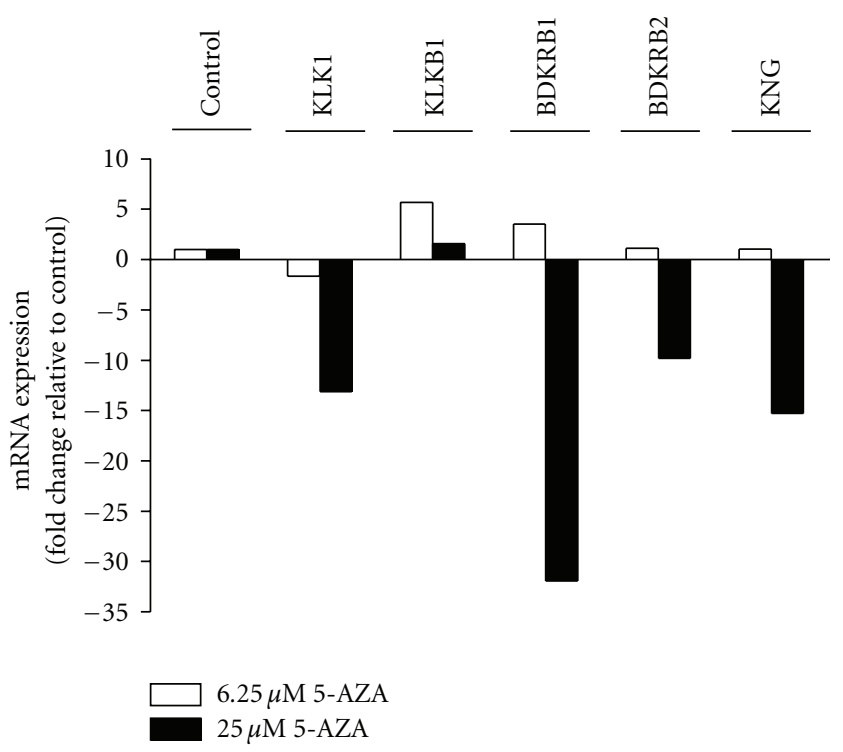

(c)

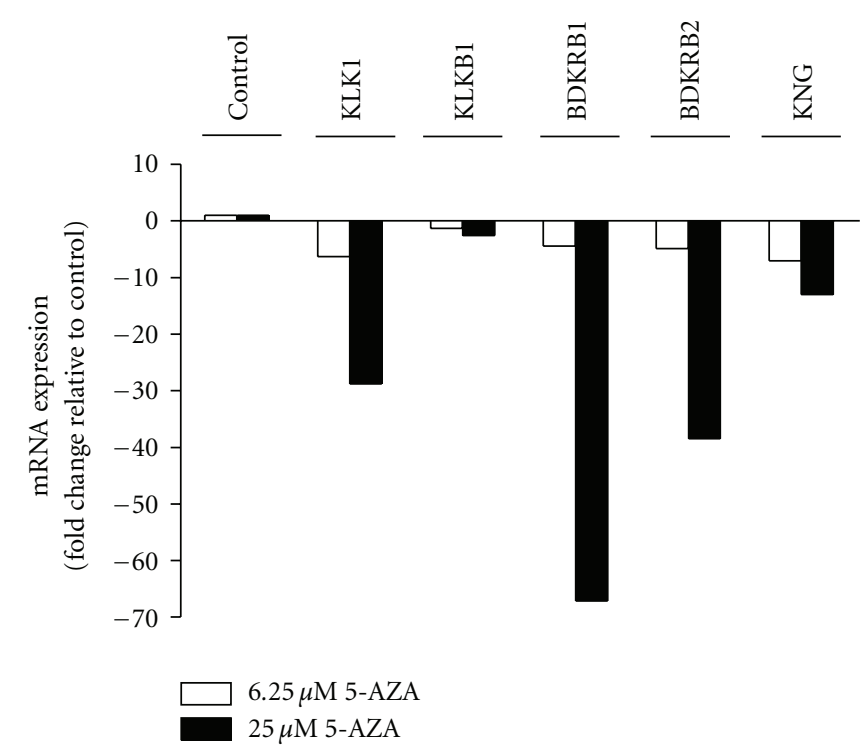

(d)

FIGURE 4: Effect of 5-azacytidine (5-AZA) on kallikrein-kinin mRNA expression in nonmalignant Met5A mesothelial cells and JU77, NO36, and LO68 malignant mesothelioma cells. (a) Fold changes in mRNA expression for tissue kallikrein (KLK1), plasma kallikrein (KLKB1), kinin $\mathrm{B}_{1}$ receptor $(B D K R B 1)$, kinin $\mathrm{B}_{2}$ receptor $(B D K R B 2)$, and high molecular weight kininogen (KNG1), relative to vehicle control (arbitrarily set at 1), in Met5A cells treated with $6.25 \mu \mathrm{M}$ (white bars) or $25 \mu \mathrm{M}$ (black bars) 5-AZA. (b) Fold changes in mRNA expression for KLK1, $K L K B 1, B D K R B 1$, and BDKRB2, relative to vehicle control (arbitrarily set at 1), in JU77 cells treated with $6.25 \mu \mathrm{M}$ (white bars) or $25 \mu \mathrm{M}$ (black bars) 5-AZA. (c) Fold changes in mRNA expression for $K L K 1, K L K B 1, B D K R B 1, B D K R B 2$, and KNG1, relative to vehicle control (arbitrarily set at 1), in NO36 cells treated with $6.25 \mu \mathrm{M}$ (white bars) or $25 \mu \mathrm{M}$ (black bars) 5-AZA. (d) Fold changes in mRNA expression for $K L K 1, K L K B 1, B D K R B 1, B D K R B 2$, and $K N G 1$, relative to vehicle control (arbitrarily set at 1), in LO68 cells treated with $6.25 \mu \mathrm{M}$ (white bars) or $25 \mu \mathrm{M}$ (black bars) 5-AZA.

expression for the kallikrein-kinin genes in lung carcinoma and malignant mesothelioma cells.

\subsection{Basal Expression of the Kallikrein-Kinin Genes in Car-} cinoma Cells of the Lung and Pleura. In the present study, expression of the kallikrein-kinin genes was greater in lung carcinoma and malignant mesothelioma cells, as compared with nonmalignant lung epithelial and pleural mesothelial cells. Increased basal expression of the kallikrein-kinin genes in carcinoma cells suggests that they may not be functioning as tumour suppressor genes, which are usually silenced in tumours [24], but rather that these are protooncogenes with the potential to induce tumorigenesis, unless silenced by DNA methylation. The concept that $\mathrm{hK} 1$ is a protooncogene 
KLK1 gene

Human chromosome 19q13.3 (4640 bp)

(56014216-56018855)

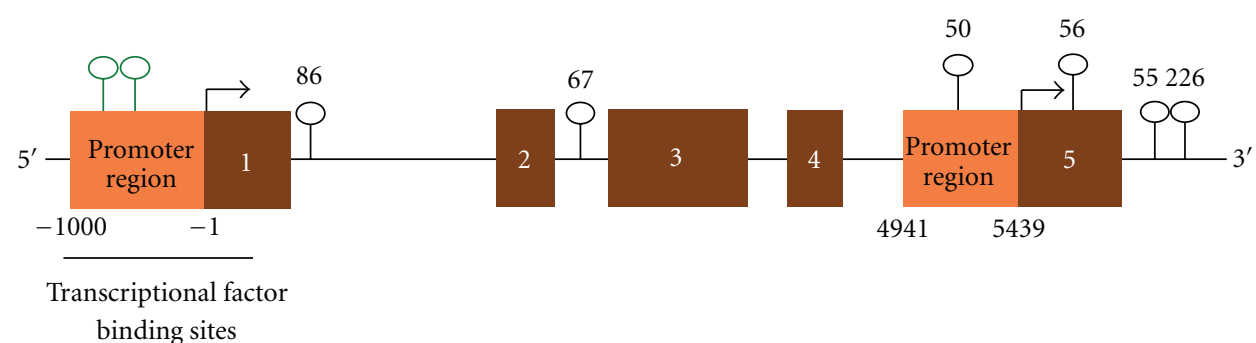

(a)
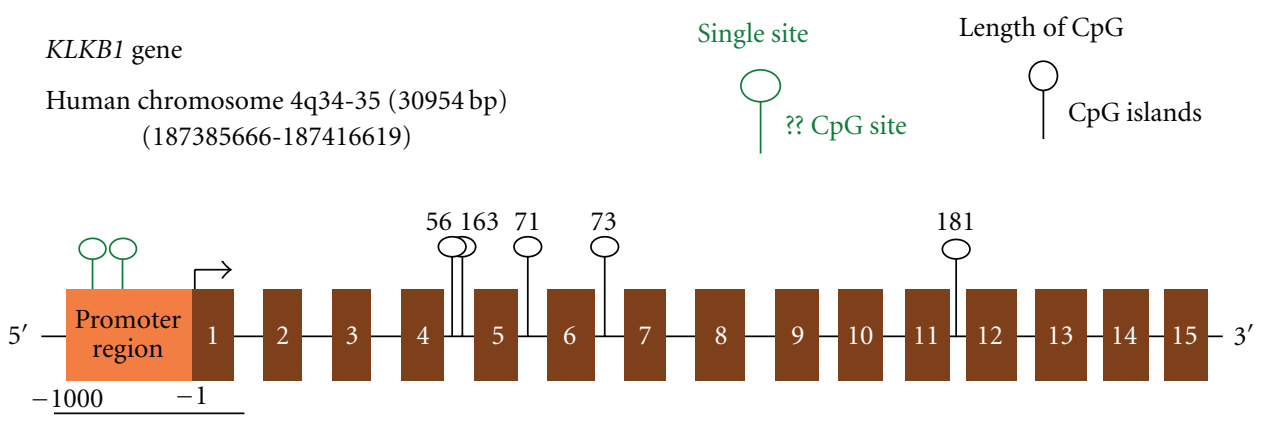

Transcriptional factor binding sites

(b)

FIgURe 5: Schematic map showing putative CpG islands in the KLK1 and KLKB1 genes. (a) The KLK1 gene on chromosome $19 \mathrm{q} 13.3$ is $4640 \mathrm{bp}$ in length. It has five exons, five introns, and two potential promoter regions extending $\sim 1000$ bases upstream of exon 1 and $\sim 500$ bases upstream of exon 5. Mapping indicated a total of six CpG islands in introns 1, 2, 4, and 5, and in exon 5. The most notable is the $\mathrm{CpG}$ island in intron 4 which is $50 \mathrm{bp}$ in length and located in a potential promoter region. (b) The KLKB1 gene on chromosome $4 \mathrm{q} 34-35$ is $30,954 \mathrm{bp}$ in length. It has 15 exons and 14 introns, with a promoter region extending $\sim 1000$ bases upstream of exon 1 . Mapping indicated a total of five CpG islands in introns 4, 5, 6, and 11 .

involved in tumorigenesis in the lung and pleura is supported by the observations that hK1 and its kinin products (i) promote metastasis and invasiveness of tumours by decreasing cell adhesion [11], (ii) stimulate DNA synthesis by activation of protein kinases [14], (iii) enhance cell proliferation [25], and (iv) increase vascular permeability and promote the migration of endothelial cells, which are hallmarks of angiogenesis $[7,11,26]$.

4.2. Expression of Kallikrein-Kinin Proteins in Carcinoma Cells of the Lung and Pleura. Greater mRNA expression generally correlated with greater expression of the kallikrein-kinin proteins in the lung cancer and mesothelioma cells, as compared with nonmalignant lung epithelial and mesothelial cells. Furthermore, expression of the kallikrein-kinin proteins was greater in H520 lung squamous carcinoma cells than in H2126 lung adenocarcinoma cells. Tissue kallikrein and the $B_{1}$ and $B_{2}$ receptor proteins showed the greatest expression, whereas kininogen protein expression was relatively low in all three lung cell types. In the mesothelioma cells, basal expression of tissue kallikrein was greater than that of plasma kallikrein, and expression of $B_{2}$ receptor protein was greater than that of $B_{1}$ receptor protein. Greater expression of $B_{2}$ receptor is in keeping with the fact that this receptor is ubiquitously and constitutively expressed, whereas expression of the $B_{1}$ receptor is generally latent or low but is induced upon cell injury $[7,27]$. Kinin $B_{2}$ receptors on the cell surface undergo a process of endocytosis upon binding of the kinin agonist and are recycled back to the surface of the cell membrane, leading to functional resensitization. Alternatively, they may be stored in the cytoplasm or targeted for degradation in lysosomes, leading to desensitization $[28,29]$. Therefore expression of $B_{2}$ receptor protein even in conditions where mRNA expression is decreased may be explained by the phenomenon of extensive receptor endocytosis, cytoplasmic storage, and recycling.

4.3. Effects of 5-Azacytidine on Expression of the KallikreinKinin Genes in Carcinoma Cells of the Lung and Pleura. Silencing of gene expression by methylation can be reversed by treatment with demethylating agents such as 5azacytidine. Reactivation of genes that are silenced by methylation indicates that the gene is functional and that DNA methylation regulates its transcription. Therefore, we determined whether 5-AZA increased the expression of the kallikrein-kinin genes in carcinoma cells of the lung and 


\section{BDKRB1 gene}

Human chromosome 14q32.1-q32.2 (8542 bp)

(95792312-95800853)

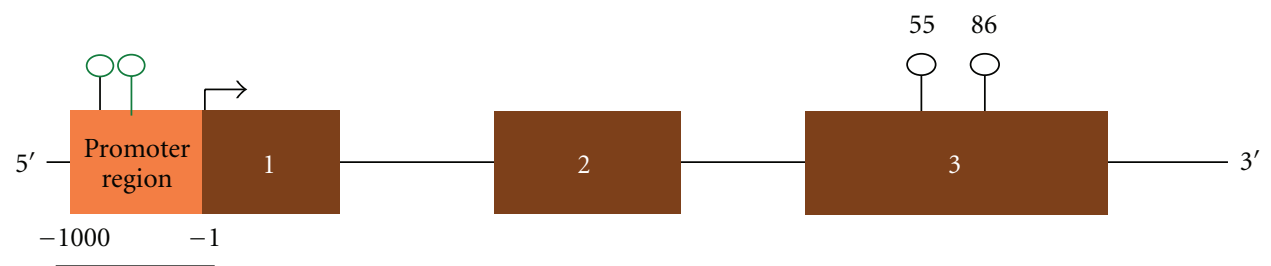

Transcriptional factor binding sites

(a)

BDKRB2 gene

Human chromosome 14q32.1-q32.2 (39593 bp) (95740950-95780542)

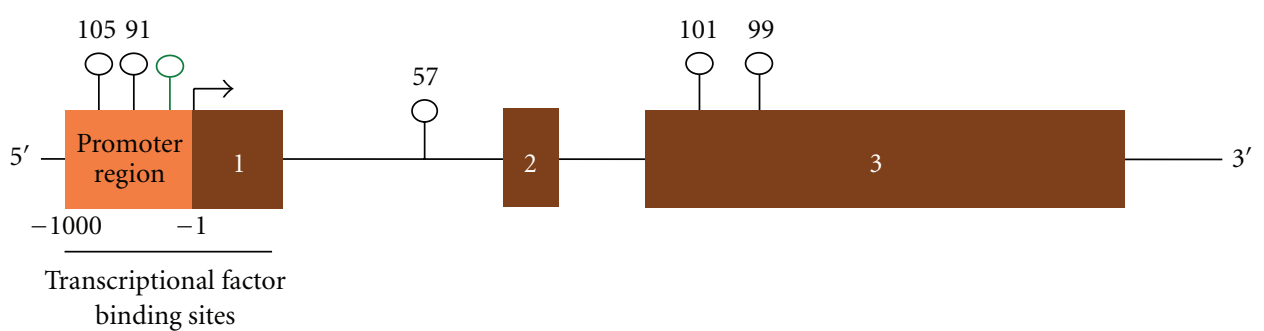

(b)

Figure 6: Schematic map showing putative CpG islands in the BDKRB1 and BDKRB2 genes. (a) The BDKRB1 gene on chromosome 14q32.132.2 is $8542 \mathrm{bp}$ in length. It has three exons and two introns, with a promoter region extending 1000 bases upstream of exon 1. Mapping indicated two CpG islands in exon 3. (b) The BDKRB2 gene is also on chromosome 14q32.1-32.2 and is 39,593 bp in length. It has three exons and two introns with a promoter region extending $~ 1000$ bases upstream of exon 1. Mapping indicated five CpG islands in intron 1, exon 3, and the promoter region. The most notable $\mathrm{CpG}$ islands were $105 \mathrm{bp}$ and $91 \mathrm{bp}$ in length and were located in the promoter region upstream of exon 1. Two CpG islands were predicted in exon 3.

pleura. The results indicated that treatment with 5-AZA increased expression of the KLKB1 gene to some extent in all lung cancer and malignant mesothelioma cell lines, except LO68. In H2126 adenocarcinoma and H520 squamous cell carcinoma cells, as well as JU77 mesothelioma cells, KLKB1 expression was upregulated 4- to 5-fold after treatment with $25 \mu \mathrm{M} 5$-AZA. These results therefore provide the first evidence that the KLKB1 gene is downregulated or silenced by aberrant methylation in carcinomas of the lung and pleura, and that KLKB1 may function as a tumour suppressor gene in these carcinomas. It is interesting to note that more than 30 years ago, Koppelmann et al. [30] observed that increased levels and activity of plasma kallikrein were associated with suppression of the growth of fibrosarcomas in hamsters.

In contrast to its effects on KLKB1 gene expression, 5-AZA had variable effects on expression of the other kallikrein-kinin genes in the different tumour cells. 5-AZA had no consistent effect on KLK1 expression in the lung carcinoma cells but downregulated KLK1 expression in NO36 and LO68 mesothelioma cells. Treatment with 5AZA resulted in marked upregulation of the BDKRB1 and
BDKRB2 genes in H520 cells but downregulation of these genes in the other tumour cells. Expression of kininogen mRNA was variable but tended to be upregulated after 5AZA treatment in H520 cells and downregulated in NO36 and LO68 cells. In the mesothelial and mesothelioma cells, 5-AZA generally decreased the expression of the kallikreinkinin genes, except for $K L K B 1$, which was upregulated in the Met-5A, JU77, and NO36 cells.

Decreased expression of some of the kallikrein-kinin genes after exposure to 5-AZA was unexpected, given that most previous studies have shown that silenced genes are reactivated after 5-AZA treatment $[31,32]$. However, there have been reports indicating downregulation of gene expression after treatment of various cells, including prostate, breast, ovarian, and lung cancer cells, with DNA methyltransferase inhibitors [33-36]. In the study by Pampalakis et al. [35], treatment with 5-aza-deoxycytidine downregulated the KLK4 and KLK5 genes in ovarian cancer cells, whereas the same genes were reactivated in similarly treated breast cancer cells. Therefore distinct epigenetic mechanisms may underlie the regulation of the various kallikrein-kinin genes in 
KNG1 gene

Human chromosome 3q27 (26624 bp)

(187917814-187944437)

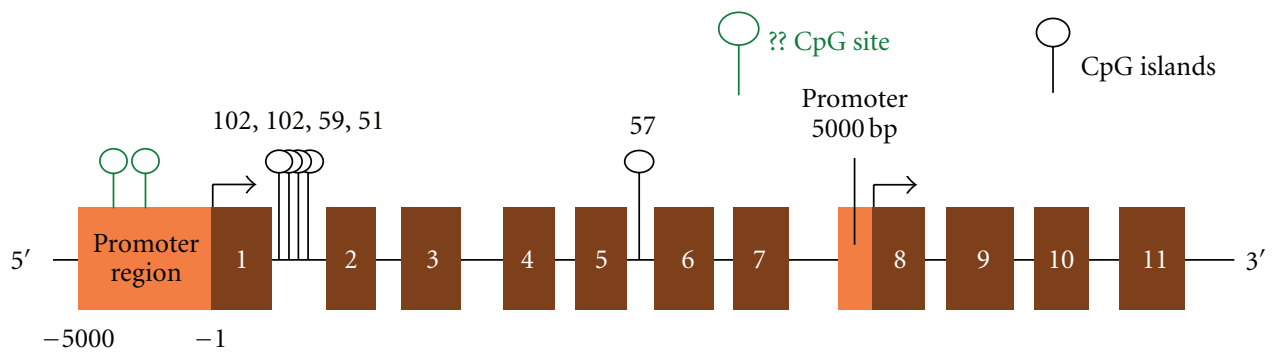

(a)

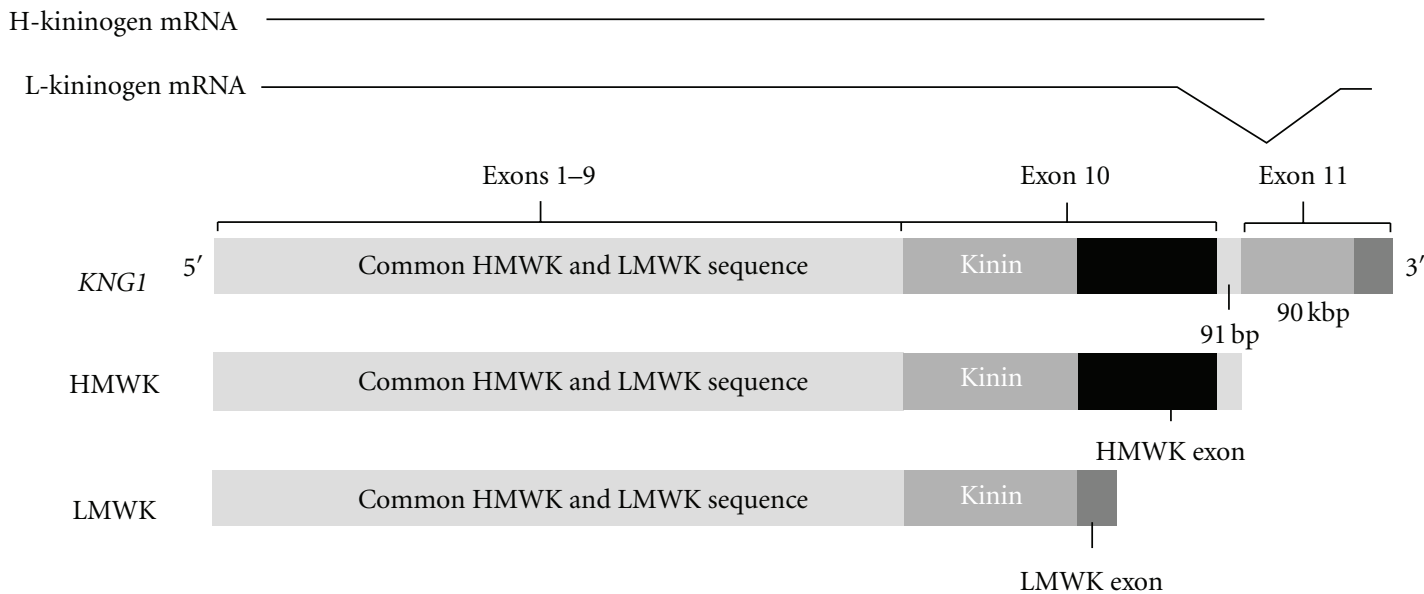

(b)

FIGURE 7: Schematic map showing putative CpG islands in the KNG1 gene and a diagram of the KNG1 gene and its two splice variants. (a) The KNG1 gene on chromosome 3q27 is 26,624 bp in length. It has 11 exons and 10 introns with two promoter regions extending $~ 5000$ base pairs upstream of exon 1 and exon 8. A total of five CpG islands were detected in introns 1 and 5. (b) The mRNA splice variants of KNG1 give rise to high molecular weight kininogen (HMWK, H-kininogen) and low molecular weight kininogen (LMWK, L-kininogen) [23].

different types of carcinomas. The reason why expression of some kallikrein-kinin genes is downregulated after treatment with 5-AZA is not known, but possible explanations are that hypomethylation of $\mathrm{CpG}$ islands allows repressor proteins to access the gene, that there may be indirect epigenetic regulation through demethylation and reactivation of the genes for silencing proteins or repressor proteins, and that 5-AZA treatment may have unknown toxic effects on the expression of some genes. However in the present study, 5-AZA had no overall toxic effect on lung cancer or mesothelioma cells, as assessed by cell proliferation assays. It is also possible that decreased expression of some of the kallikrein-kinin genes after 5-AZA treatment may be due to the existence of multiple splice variants or the use of alternative promoters, as previously observed for KLK6 [37] and KLK11 [38].

4.4. Mapping of Putative CPG Islands in the Kallikrein-Kinin Genes. Although DNA methylation at $\mathrm{CpG}$ islands in the promoter region is known to cause gene silencing [39], the specific details of the demethylating effects of 5-AZA on particular genes are not clear. We therefore mapped the putative $\mathrm{CpG}$ islands in the five kallikrein-kinin genes and their relationships with the promoter regions, transcription factor binding sites, and exons of these genes (Figures 5, 6, and 7). The maps showed that for the KLK1 and BDKRB2 genes there were $\mathrm{CpG}$ islands located in putative promoter regions. However, the $K L K B 1, B D K R B 1$, and $K N G 1$ genes did not appear to have $\mathrm{CpG}$ islands located in their putative promoter regions, raising the question as to how methylation might affect the expression of these genes. Besides methylation of $\mathrm{CpG}$ islands in promoter regions, it is possible that regulatory elements of genes are methylated, which may affect gene expression by blocking essential transcription factor motifs. Furthermore, gene regulatory elements may not necessarily be located on the same chromosome or in close proximity to the genes that they regulate [40]; thus methylation of $\mathrm{CpG}$ islands in regulatory elements at distal loci may affect expression of the kallikrein-kinin genes.

\section{Conclusion}

The general suppression of kallikrein-kinin gene expression, except for the KLKB1 gene, in lung carcinoma and mesothelioma cells treated with 5-AZA, suggests that these 
genes are more likely to function as oncogenes rather than tumour suppressor genes. KLK1 may function as an oncogene that transforms normal cells and increases tumour invasiveness and metastasis. In contrast, the general increase in expression of KLKB1 after 5-AZA treatment suggests that it may be a tumour suppressor gene with a critical role in the formation of new blood vessels in cancers of the lung and pleura. Further studies involving bisulphite sequencing and alignment of the resulting sequences are necessary to detect CpG motifs in the kallikrein-kinin genes that are differentially methylated between cancerous and noncancerous cells.

Advances in the characterization of epigenetic modifications in cancer cells have improved our understanding of the mechanisms of gene regulation. DNA methylation may be a promising target for potential therapeutic strategies [41], and demethylating drugs may be beneficial in the treatment of solid tumours of the lung and pleura. In addition, detection of methylated DNA in plasma of cancer patients may provide a noninvasive means of diagnosis or monitoring responses to treatment. Knowledge of the epigenetic changes that occur in specific genes should provide us with biomarkers for following cancer progression, as well as new tools for cancer therapy.

This paper describes for the first time important new findings on epigenetic regulation of the kallikrein-kinin genes by DNA methylation in lung cancer and mesothelioma cells. Our results show that following treatment with the demethylating agent, 5-azacytidine, expression of plasma kallikrein mRNA was consistently increased in both lung carcinoma and mesothelioma cells, whereas expression of tissue kallikrein, kininogen, and kinin $\mathrm{B}_{1}$ and $\mathrm{B}_{2}$ receptor mRNA was either decreased or unchanged. Increased expression of plasma kallikrein after 5-azacytidine treatment suggests that it may function as a tumour suppressor gene with an important and novel role in regulating the vasculature of cancers of the lung and pleura.

\section{References}

[1] A. G. Schwartz, G. M. Prysak, C. H. Bock, and M. L. Cote, "The molecular epidemiology of lung cancer," Carcinogenesis, vol. 28, no. 3, pp. 507-518, 2007.

[2] A. Risch and C. Plass, "Lung cancer epigenetics and genetics," International Journal of Cancer, vol. 123, no. 1, pp. 1-7, 2008.

[3] B. P. Shelton, N. L. Misso, O. M. Shaw, E. Arthaningtyas, and K. D. Bhoola, "Epigenetic regulation of human epithelial cell cancers," Current Opinion in Molecular Therapeutics, vol. 10, no. 6, pp. 568-578, 2008.

[4] J. T. Hodgson and A. Darnton, "The quantitative risks of mesothelioma and lung cancer in relation to asbestos exposure," Annals of Occupational Hygiene, vol. 44, no. 8, pp. 565-601, 2000.

[5] M. Gulumian and T. A. Kilroe-Smith, "Crocidolite-induced lipid peroxidation in rat lung microsomes. I. Role of different ions," Environmental Research, vol. 43, no. 1, pp. 267-273, 1987.

[6] D. W. Kamp, P. Graceffa, A. W. Pryor, and S. A. Weitzman, "The role of free radicals in asbestos-induced diseases," Free Radical Biology and Medicine, vol. 12, no. 4, pp. 293-315, 1992.
[7] K. Bhoola, R. Ramsaroop, J. Plendl, B. Cassim, Z. Dlamini, and S. Naicker, "Kallikrein and kinin receptor expression in inflammation and cancer," Biological Chemistry, vol. 382, no. 1, pp. 77-89, 2001.

[8] J. A. Clements, J. Hooper, Y. Dong, and T. Harvey, "The expanded human kallikrein $(K L K)$ gene family: genomic organisation, tissue-specific expression and potential functions," Biological Chemistry, vol. 382, no. 1, pp. 5-14, 2001.

[9] J. A. Clements, N. M. Willemsen, S. A. Myers, and Y. Dong, "The tissue kallikrein family of serine proteases: functional roles in human disease and potential as clinical biomarkers," Critical Reviews in Clinical Laboratory Sciences, vol. 41, no. 3, pp. 265-312, 2004.

[10] E. P. Diamandis and G. M. Yousef, "Human tissue kallikreins: a family of new cancer biomarkers," Clinical Chemistry, vol. 48, no. 8, pp. 1198-1205, 2002.

[11] C. A. Borgono, I. P. Michael, and E. P. Diamandis, "Human tissue kallikreins: physiologic roles and applications in cancer," Molecular Cancer Research, vol. 2, no. 5, pp. 257-280, 2004.

[12] J. S. Taub, R. Guo, L. M. Leeb-Lundberg, J. F. Madden, and Y. Daaka, "Bradykinin receptor subtype 1 expression and function in prostate cancer," Cancer Research, vol. 63, no. 9, pp. 2037-2041, 2003.

[13] R. A. Roberts and W. J. Gullick, "Bradykinin receptor number and sensitivity to ligand stimulation of mitogenesis is increased by expression of a mutant ras oncogene," Journal of Cell Science, vol. 94, part 3, pp. 527-535, 1989.

[14] A. Graness, A. Adomeit, R. Heinze, R. Wetzker, and C. Liebmann, "A novel signalling pathway of bradykinin in the human colon carcinoma cell line SW-480 involves sequential activation of $\mathrm{G}_{q / 11}$ protein, phosphatidylinositol 3-kinase $\beta$, and protein kinase C $\varepsilon$," Journal of Biological Chemistry, vol. 273, no. 48, pp. 32016-32022, 1998.

[15] J. M. Stewart, L. Gera, D. C. Chan, E. T. Whalley, W. L. Hanson, and J. S. Zuzack, "Potent, long-acting, orally-active bradykinin antagonists for a wide range of applications," Immunopharmacology, vol. 36, no. 2-3, pp. 167-172, 1997.

[16] D. C. Chan, L. Gera, J. M. Stewart et al., "Bradykinin antagonist dimer, CU201, inhibits the growth of human lung cancer cell lines in vitro and in vivo and produces synergistic growth inhibition in combination with other antitumor agents," Clinical Cancer Research, vol. 8, no. 5, pp. 1280-1287, 2002.

[17] J. Chee, A. Naran, N. L. Misso, P. J. Thompson, and K. D. Bhoola, "Expression of tissue and plasma kallikreins and kinin $\mathrm{B}_{1}$ and $\mathrm{B}_{2}$ receptors in lung cancer," Biological Chemistry, vol. 389, no. 9, pp. 1225-1233, 2008.

[18] J. Chee, J. Singh, A. Naran, N. L. Misso, P. J. Thompson, and K. D. Bhoola, "Novel expression of kallikreins, kallikreinrelated peptidases and kinin receptors in human pleural mesothelioma," Biological Chemistry, vol. 388, no. 11, pp. 1235-1242, 2007.

[19] D. Hanahan and R. A. Weinberg, "The hallmarks of cancer," Cell, vol. 100, no. 1, pp. 57-70, 2000.

[20] A. Miremadi, M. Z. Oestergaard, P. D. Pharoah, and C. Caldas, "Cancer genetics of epigenetic genes," Human Molecular Genetics, vol. 16, no. 1, pp. R28-R49, 2007.

[21] P. A. Jones and S. B. Baylin, "The fundamental role of epigenetic events in cancer," Nature Reviews Genetics, vol. 3, no. 6, pp. 415-428, 2002.

[22] K. J. Livak and T. D. Schmittgen, "Analysis of relative gene expression data using real-time quantitative PCR and the 2$(\Delta \Delta \mathrm{C}(\mathrm{T}))$ method," Methods, vol. 25, no. 4, pp. 402-408, 2001. 
[23] N. Kitamura, Y. Takagaki, S. Furuto, T. Tanaka, H. Nawa, and S. Nakanishi, "A single gene for bovine high molecular weight and low molecular weight kininogens," Nature, vol. 305, no. 5934, pp. 545-549, 1983.

[24] C. J. Sherr, "Principles of tumor suppression," Cell, vol. 116, no. 2, pp. 235-246, 2004.

[25] D. Srinivasan, A. H. Kosaka, D. V. Daniels, A. P. Ford, and A. Bhattacharya, "Pharmacological and functional characterization of bradykinin $\mathrm{B}_{2}$ receptor in human prostate," European Journal of Pharmacology, vol. 504, no. 3, pp. 155-167, 2004.

[26] J. K. Wright, J. H. Botha, and S. Naidoo, "Influence of the kallikrein-kinin system on prostate and breast tumour angiogenesis," Tumor Biology, vol. 29, no. 2, pp. 130-136, 2008.

[27] L. M. Leeb-Lundberg, F. Marceau, W. Müller-Esterl, D. J. Pettibone, and B. L. Zuraw, "International union of pharmacology. XLV. Classification of the kinin receptor family: from molecular mechanisms to pathophysiological consequences," Pharmacological Reviews, vol. 57, no. 1, pp. 27-77, 2005.

[28] D. R. Bachvarov, S. Houle, M. Bachvarova, J. Bouthillier, A. Adam, and F. Marceau, "Bradykinin B(2) receptor endocytosis, recycling, and down-regulation assessed using green fluorescent protein conjugates," Journal of Pharmacology and Experimental Therapeutics, vol. 297, no. 1, pp. 19-26, 2001.

[29] J. Enquist, C. Skröder, J. L. Whistler, and L. M. Leeb-Lundberg, "Kinins promote $B_{2}$ receptor endocytosis and delay constitutive $\mathrm{B}_{1}$ receptor endocytosis," Molecular Pharmacology, vol. 71, no. 2, pp. 494-507, 2007.

[30] L. E. Koppelmann, T. C. Moore, and D. D. Porter, "Increased plasma kallikrein activity and tumour growth suppression associated with intralesional bradykinin injections in hamsters," Journal of Pathology, vol. 126, no. 1, pp. 1-10, 1978.

[31] L. O. Dannenberg and H. J. Edenberg, "Epigenetics of gene expression in human hepatoma cells: expression profiling the response to inhibition of DNA methylation and histone deacetylation,” BMC Genomics, vol. 7, p. 181, 2006.

[32] K. Roder, M. J. Latasa, and H. S. Sul, "Silencing of the mouse $\mathrm{H}-$ rev107 gene encoding a class II tumor suppressor by CpG methylation," Journal of Biological Chemistry, vol. 277, no. 34, pp. 30543-30550, 2002.

[33] Y. Kitagawa, S. Kyo, M. Takakura et al., "Demethylating reagent 5-azacytidine inhibits telomerase activity in human prostate cancer cells through transcriptional repression of hTERT," Clinical Cancer Research, vol. 6, no. 7, pp. 2868-2875, 2000.

[34] B.-Z. Yuan, A. M. Jefferson, N. C. Popescut, and S. H. Reynolds, "Aberrant gene expression in human non small cell lung carcinoma cells exposed to demethylating agent 5Aza-2'-deoxycytidine," Neoplasia, vol. 6, no. 4, pp. 412-419, 2004.

[35] G. Pampalakis, E. P. Diamandis, and G. Sotiropoulou, "The epigenetic basis for the aberrant expression of kallikreins in human cancers," Biological Chemistry, vol. 387, no. 6, pp. 795799, 2006.

[36] L. Menendez, D. Walker, L. V. Matyunina et al., "Identification of candidate methylation-responsive genes in ovarian cancer," Molecular Cancer, vol. 6, p. 10, 2007.

[37] G. Pampalakis, L. Kurlender, E. P. Diamandis, and G. Sotiropoulou, "Cloning and characterization of novel isoforms of the human kallikrein 6 gene," Biochemical and Biophysical Research Communications, vol. 320, no. 1, pp. 5461, 2004.
[38] S. Mitsui, T. Nakamura, A. Okui, K. Kominami, H. Uemura, and N. Yamaguchi, "Multiple promoters regulate tissuespecific alternative splicing of the human kallikrein gene, KLK11/hippostasin," FEBS Journal, vol. 273, no. 16, pp. 36783686, 2006.

[39] M. G. Goll and T. H. Bestor, "Eukaryotic cytosine methyltransferases," Annual Review of Biochemistry, vol. 74, pp. 481-514, 2005.

[40] C. G. Spilianakis, M. D. Lalioti, T. Town, G. R. Lee, and R. A. Flavell, "Interchromosomal associations between alternatively expressed loci," Nature, vol. 435, no. 7042, pp. 637-645, 2005.

[41] A. P. Feinberg, R. Ohlsson, and S. Henikoff, "The epigenetic progenitor origin of human cancer," Nature Reviews Genetics, vol. 7, no. 1, pp. 21-33, 2006. 


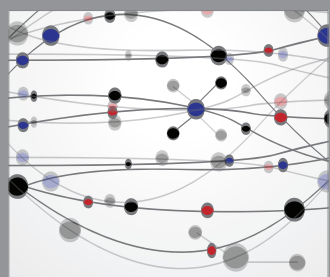

The Scientific World Journal
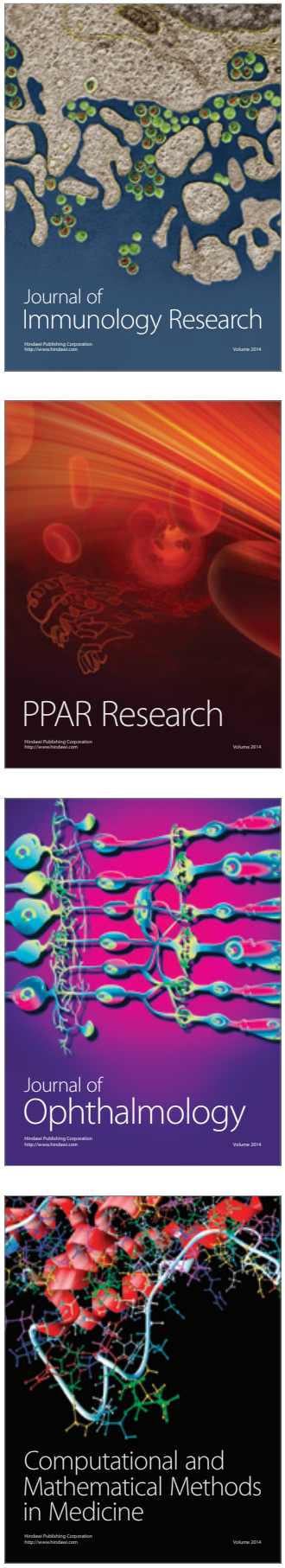

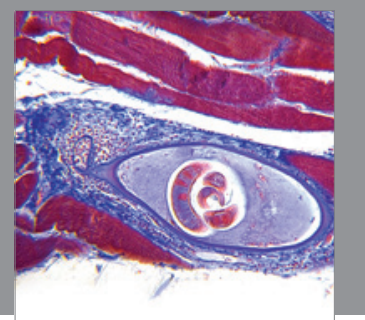

Gastroenterology

Research and Practice
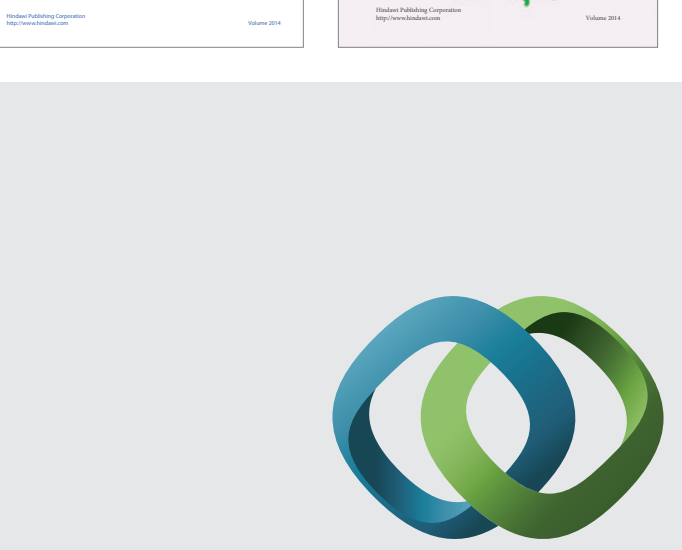

\section{Hindawi}

Submit your manuscripts at

http://www.hindawi.com
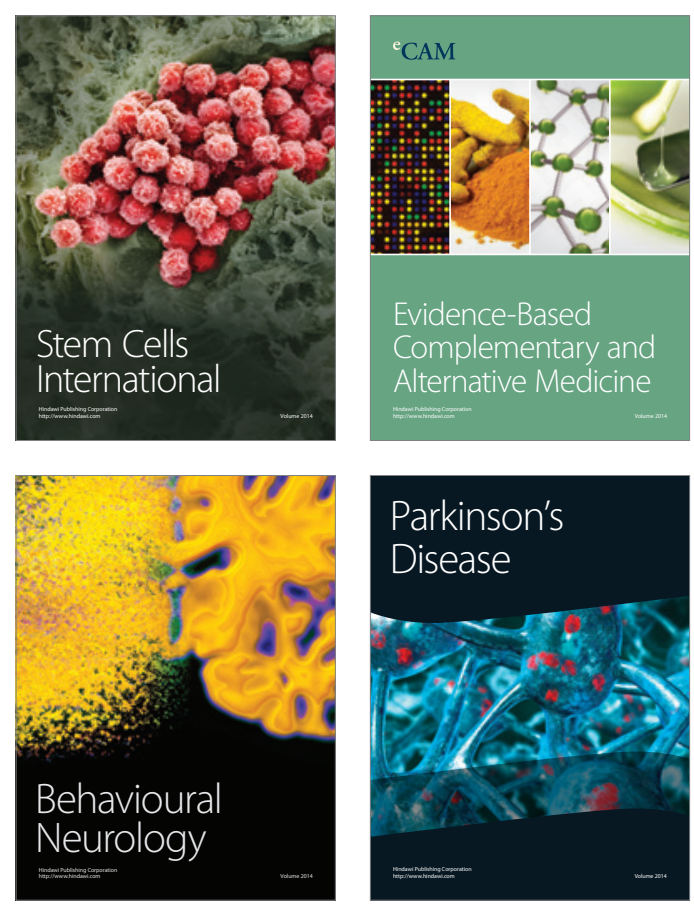

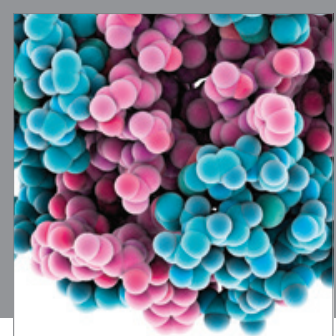

Journal of
Diabetes Research

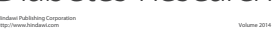

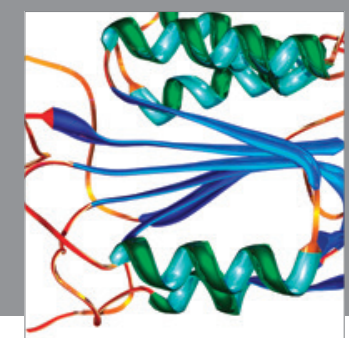

Disease Markers
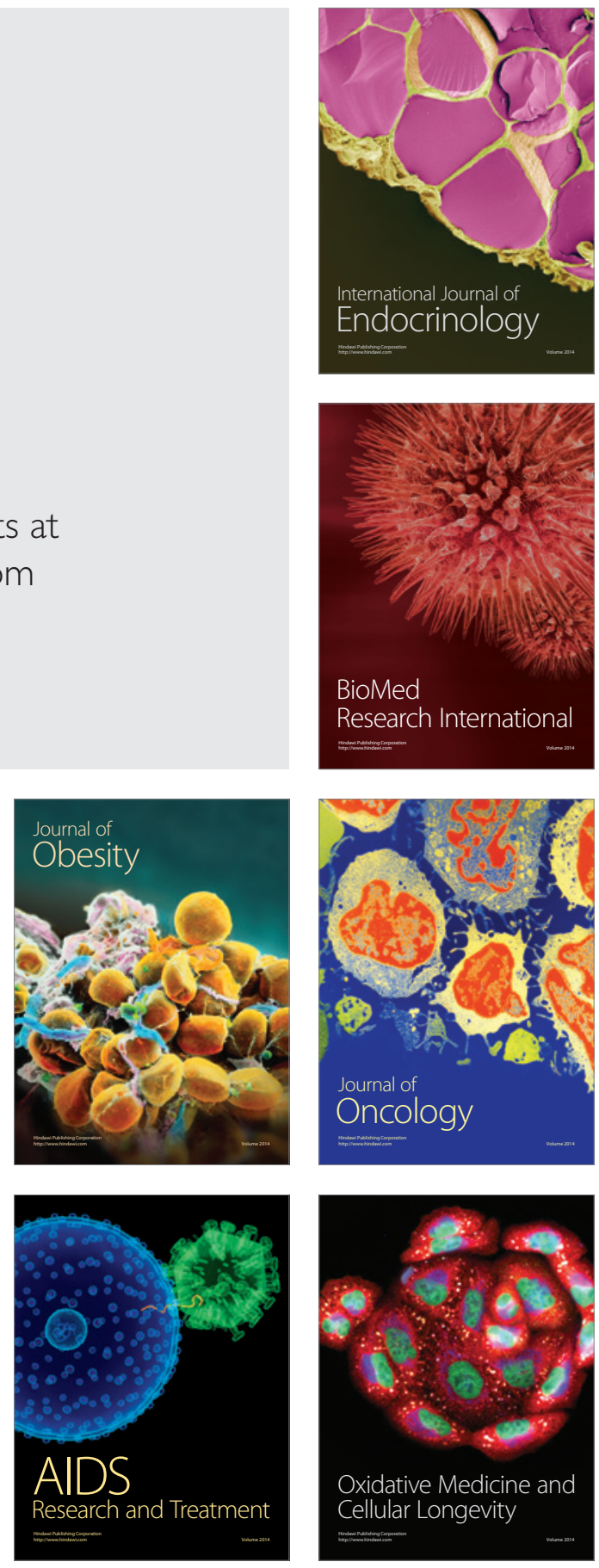